\title{
Increasing incidence of aortic aneurysms in England and Wales
}

\author{
F G R Fowkes, C C A Macintyre, C V Ruckley
}

\begin{abstract}
The numbers of patients being admitted to hospital with aortic aneurysms have increased recently. A study was carried out to try to find out whether this was a true increase in incidence or whether it could be attributable to more accurate diagnosis and better surgical techniques. From analyses of routine statistics it was found that from 1950 to 1984 age standardised mortality rose 20 -fold in men to $47 \cdot 1$ per 100000 population and 11 -fold in women to 22.2 per 100000 and that this was mainly due to more deaths from abdominal aneurysms. Hospital admissions of men with abdominal aneurysms were found to have increased steadily from 1968 to 1983 , but the increase for women admitted did not begin until 1978. An increase in both emergency and elective admissions and only a marginal fall in deaths in hospital (from $45 \%$ to $39 \%$ ) suggest that admissions for abdominal aneurysms increased across a wide range of severity of disease.

It is concluded for the following reasons that the true incidence of aortic aneurysms, particularly abdominal aneurysms, has been increasing in England and Wales: the trends are not wholly compatible with advances in diagnosis and surgery, there are inconsistencies by age and sex, and increases have occurred in the number of complicated as well as uncomplicated cases.
\end{abstract}

\section{Introduction}

The recent increase in the numbers of patients presenting with aortic aneurysms is well known to vascular surgeons. In Scotland the number of admissions of patients over 55 years of age with an abdominal aneurysm increased from 25.8 per 100000 population in 1971 to 63.6 per 100000 in 1984. . Similar $^{\prime}$ changes occurred in Australia and the United States. ${ }^{23}$ The reasons for these higher rates, particularly of abdominal aneurysms, are not clear. Has there been a true increase in population incidence? Has case ascertainment improved owing to better surgical techniques and the advent of diagnostic procedures such as ultrasound and computed tomography? We examined trends in mortality and admissions for aortic aneurysms in England and Wales to try to explain this.

\section{Methods}

We obtained the number of deaths due to aortic aneurysms in England and Wales from 1950 to 1983 from routine statistics on mortality. ${ }^{+i}$ The following International Classification of Diseases diagnostic codes were examined: ICD 451 (1950-67); 441 (196873); 441.0, 1, 2, 9 (1974-8); and 441.0-5, 9 (1979-83). Aortic aneurysms due to syphilis were not included. Mortality statistics by type of aneurysm, such as abdominal or thoracic, were available from 1974 to 1983 only. Population figures were mid-year estimates. ${ }^{+5}$ Age standardisation was performed by the direct method using an arbitrary population (male age structure in 1981) as the standard.

We obtained the numbers of discharges and deaths of patients with a diagnosis of aortic aneurysm from 1968 to 1983 from the Hospital In-Patient Enquiry." Data on abdominal aneurysms were obtained by special request from the Office of Population Censuses and Surveys. The following diagnostic codes were used to identify abdominal aneurysms: ICD 441.2 (1968-78) and 441.3-4 (1979-83). Since the Hospital In-Patient Enquiry comprises an approximate 1 in 10 sample suitable multiplying factors were applied. Statistics on abdominal aneurysms for before 1968 were not available because of the lack of four digit coding. Codes for operations were not suitable for analysis because many operations on abdominal aneurysms were incorporated into a general category of operations on abdominal vessels.

\section{Results}

MORTALITY

In England and Wales the number of deaths due to aortic aneurysm in men aged over 40 increased from 202 in 1950 to 4668 in 1984 and in women from 201 to 2591. The corresponding age standardised mortality for men increased 20 -fold from $2 \cdot 4$ to $47 \cdot 1$ per 100000 and for women 11 -fold from $2 \cdot 0$ to $22 \cdot 2$ per 100000 . Figure 1 shows that rates rose steadily throughout 1950-84. The changes were, however, relatively

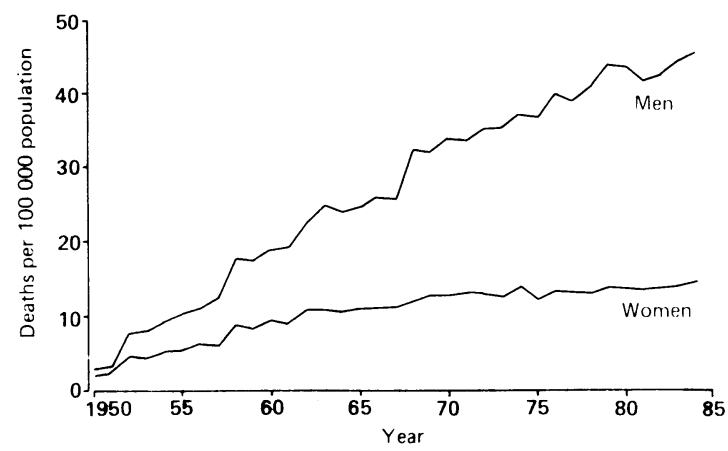

FIG 1-Age standardised mortality due to aortic aneurysm for men and women, 1950 to 1984 in England and Wales

greater in earlier years. For example, the rates for men increased 7.5 times between 1950 and 1960 and only 2.5 times between 1960 and 1984. Analysis of age specific rates indicated that these upward trends were slightly more pronounced with increasing age and were static from 1960 among younger age groups (under 60). Analyses of birth cohorts showed that mortality within each five year cohort born since 1860 increased during 1950 to 1984 with no dramatic differences observed between the cohorts other than those due to their different ages. 
The numbers of deaths by type of aneurysm were available from 1974, but the type was not specified for one quarter of deaths each year. From 1974 to 1984 the number of deaths due to dissecting, thoracic, and abdominal aortic aneurysms increased, but the number due to abdominal aneurysms rose to a much greater extent and accounted for four fifths of the increase in numbers of specified deaths (table I).

TABLE I - Numbers of deaths by type of aneurysm, 1974 and 1984

\begin{tabular}{lrrc}
\hline & \multicolumn{2}{c}{ No of deaths } & $\begin{array}{c}\text { Percentage increase in } \\
\text { number of deaths } \\
1974-84\end{array}$ \\
\cline { 2 - 3 } Type of aneurysm & 1974 & 1984 & 10 \\
\hline Dissecting & 1596 & 1750 & 17 \\
Thoracic & 576 & 671 & 53 \\
Abdominal & 1900 & 2898 & 47 \\
Not specified & 1321 & 1940 & 35
\end{tabular}

\section{HOSPITAL ADMISSIONS}

Trends in hospital admissions were also more pronounced for abdominal aneurysms than other aneurysms. Figure 2 shows that for men crude admission rates of discharges and deaths with a diagnosis of abdominal aortic aneurysm increased steadily from $2 \cdot 4$ per 100000 population in 1968 to 11.3 per 100000 in 1983 . (Figure 2 is based on three year moving averages to smooth year by year fluctuations.) Admission rates for women remained constant from 1968 to 1977 , subsequently increasing at the same rate as for men to three per 100000 in 1983 . Admission rates for other aortic aneurysms in men showed a small increase only from five per 100000 in 1968 to seven per 100000 in 1983 and for women remained constant. Analysis of age specific admission rates for men with abdominal aneurysm showed that trends were consistent within age groups; for women upward trends since 1977 appeared to be slightly greater in younger age groups, but this interpretation may be erroneous owing to small numbers.

During 1968-83 emergency admissions of patients with abdominal aneurysms increased over three-

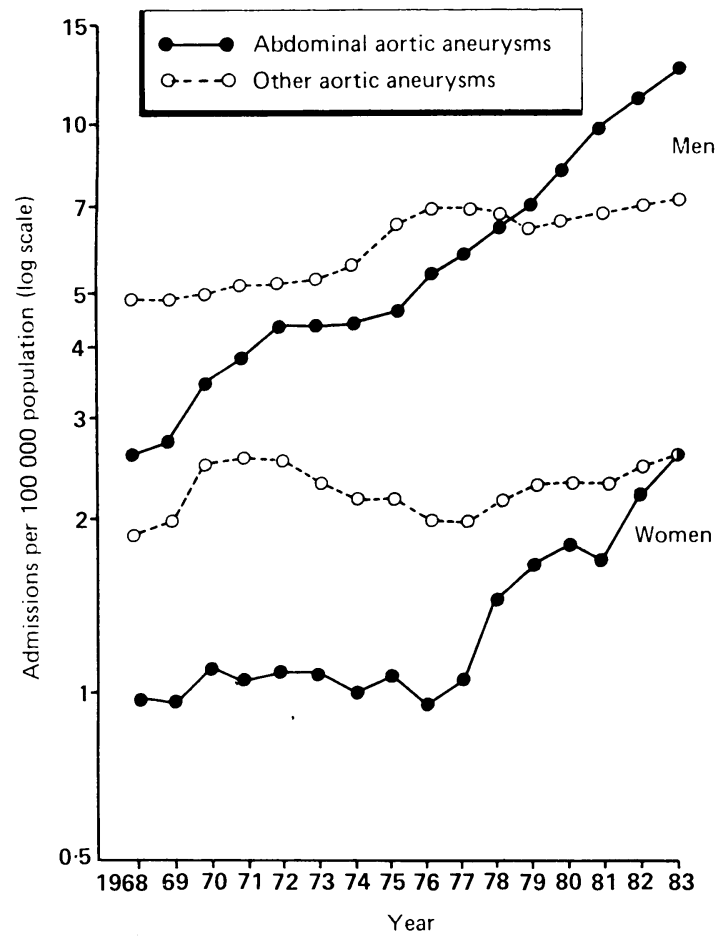

FIG 2-Rates of hospital admission of men and women who were discharged with a diagnosis of aortic aneurysm, abdominal aneurysm, and other, 1968 to 1983 in England and Wales. (Three year moving averages)
TABLE II - Number of patients admitted to hospital and discharged with a diagnosis of abdominal aortic aneurysm, number of emergency admissions, and number of deaths four yearly, 1968-83

\begin{tabular}{lccc}
\hline & $\begin{array}{c}\text { No of } \\
\text { admissions }\end{array}$ & $\begin{array}{c}\text { No of emergencies } \\
\text { (\% of admissions) }\end{array}$ & $\begin{array}{c}\text { No of deaths } \\
\text { (\% of admissions) }\end{array}$ \\
\hline $1968-71$ & 3967 & $2484(63)$ & $1791(45)$ \\
$1972-5$ & 5199 & $3348(64)$ & $2309(44)$ \\
$1976-9$ & 7317 & $4285(59)$ & $3066(42)$ \\
$1980-3$ & 11390 & $6360(56)$ & $4380(39)$
\end{tabular}

fold, but the proportion of admissions that were emergencies showed no consistent trend, varying yearly between $52 \%$ and $71 \%$. Overall, however, a slightly smaller percentage of admissions were emergencies in later years (table II). The proportion of patients who died in hospital also varied considerably yearly, showing a slight decrease over the 16 years. This reduction occurred among both sexes and in all age groups so that the risk of dying remained higher for men than women and at older ages.

\section{Discussion}

The substantial rise in age standardised mortality in the 1950s, with the possible exception of an abrupt increase in 1952 owing to a change in coding practice, might have been due primarily to a true increase in incidence as there were no important advances in diagnosis or surgery during this period to improve case ascertainment. The relatively smaller increase in mortality in the late 1960s and 1970s may have been due to advances in surgical treatment reducing case fatality and hence restraining the overall mortality. On the other hand, there may have been a greater tendency to intervene surgically, which may have resulted in a higher case ascertainment and a corresponding increase in the number of deaths ascribed to aortic aneurysm. Interestingly, there was no evidence of a more pronounced increase in the 1970s associated with the advent of abdominal ultrasound and computed tomography. Any influence of changes in hospital practices on the ascertainment of deaths, however, may have been ameliorated by one half to three quarters of the deaths from aortic aneurysm in the United Kingdom occurring outside hospital. ${ }^{7.9}$

Further evidence of a true increase in incidence may be derived from the results of necropsy studies which suggest that the increase in mortality from aortic aneurysms (excluding syphilitic aneurysms) began earlier than $1950^{1011}$ and was due mostly to an increase in the number of deaths from abdominal aneurysms. The results of our study also suggest that more recent trends in mortality were primarily due to more deaths occurring from abdominal aneurysms. This is further substantiated by our hospital admission data, which show a relatively small change in the numbers of admissions for non-abdominal aneurysms.

Our data on hospital admissions for abdominal aneurysms also suggest that changes in diagnostic and surgical practice were not the only influence on trends. Men and women might have been expected to have been equally affected, whereas admission rates for women did not begin to increase until 1978 in contrast to the steady increase in rates for men from 1968 to 1983. In the younger age groups rates for women showed a relatively greater increase, which was similar to the findings in Western Australia. ${ }^{2}$ Though diagnostic ultrasound was available in the early 1970 s, among men there was no upturn at this time, admissions continuing to increase at the same rate. This lack of consistency by age and sex strongly suggests that the trends were influenced by changes in the incidence of disease. The increase in admissions was unlikely to be due simply to more readmissions 
because trends in operating rates, as shown elsewhere, ${ }^{12}$ have been increasing faster than admission rates with relatively more patients proceeding to surgery when admitted.

Emergency admissions of patients with abdominal aneurysms increased more than threefold from 1968 to 1983. Some of the increase might have been due to better diagnosis of patients who were emergency admissions but this is unlikely. Indeed, local studies in the United Kingdom have shown a dramatic rise in emergency admissions for ruptured aortic aneurysm, suggesting a real upward trend in disease rates. ${ }^{912}$ The slight reductions in the ratios of emergency to elective admissions and of deaths in admissions might imply that more admissions were for uncomplicated aneurysms, but the reduction in case fatality was probably due to considerable improvements in surgical and anaesthetic technique in carrying out both elective and emergency operations.' Undoubtedly, as Melton et al found in Rochester, Minnesota, ${ }^{3}$ more small uncomplicated asymptomatic aneurysms were being detected, but not exclusively so. Thus it appears that admission rates increased across the full range of severity, implying a true change in incidence and not just improved case ascertainment.

Thus the trends that were not wholly compatible with advances in diagnosis and surgery, the inconsistencies by age and sex, and the increase in complicated as well as uncomplicated cases all suggest that the true incidence of aortic aneurysms, particularly abdominal aneurysms, has been increasing recently in England and Wales. What then are the implications for medical care? Undoubtedly, the burden on vascular surgery units will increase, not only because more patients will be admitted but also because many surgeons recognise the benefits of operating on small abdominal aneurysms. ${ }^{1314}$ An increasing incidence may also influence the discussion on the value of screening for asymptomatic abdominal aneurysms. ${ }^{15-1 ?}$ The diagnostic yield of abdominal aneurysms greater than $4 \mathrm{~cm}$ diameter in men aged $65-80$ years is only about $2 \%,{ }^{16}{ }^{17}$ but a higher detection rate with an increasing incidence would affect the balance between the costs, risks, and benefits of screening.

I Naylor AR, Webb J, Fowkes FGR, Ruckley CV. Trends in abdominal aortic aneurysm surgery in Scotland (1971-1984). European fournal of Vascular Surgery 1988:2:217-21.

2 Castleden WM, Mercer JC, and members of the West Australian Vascular Service. Abdominal aortic aneurysms in Western Australia: descriptive epidemiology and patterns of rupture. Brf Surg 1985;72:109-12.

3 Melton LJ, Bickerstaff LK, Hollier LH, et al. Changing incidence of abdominal aortic aneurysms: a population-based study. Am $\mathcal{J}$ Epidemiol 1984;120:379-86

4 Registrar General. Statistical review of England and Wales. Part I, tables, medical. London: HMSO, yearly 1950 to 1973.

5 Office of Population Censuses and Surveys. Mortality statistics. England and Wales. London: HMSO, yearly 1974 to 1983 . (Series DHI.)

6 Department of Health and Social Security, Office of Population Censuses and Surveys. Hospital in-patient enquiry. Main tables. London: HMSO, yearly 1968 to 1983

7 Talbot S, Langman MJS. Epidemiological features of ruptured, dissecting and saccular aneurvsms. Postgrad Med f 1972;48:414-6.

8 Armour RH. Survivors of ruptured abdominal aortic aneurysm: the iceberg's tip. Br Med f 1977;ii: 1055-7.

9 Ingoldby $\mathrm{CJH}$, Wujanto R, Mitchell JE. Impact of vascular surgery on community mortality from ruptured aneurysms. Br $\mathcal{f}$ Surg 1986;73:551-3.

0 Maniglia R, Gregory JE. Increasing incidence of arteriosclerotic aortic aneurysms: analysis of six thousand autopsies. Archives of Pathology 1952;54:298-305.

11 Gore I, Hirst AE Jr. Arteriosclerotic aneurysms of the abdominal aorta: a review. Prog Cardiovasc Dis 1973;16:113-49.

12 Jenkins AMcL, Ruckley CV, Nolan B. Ruptured abdominal aortic aneurysm Br f Surg 1986;73:395-8.

13 Collin J. Elective surgery for small abdominal aortic aneurysms. Lancet $1987 ; \mathrm{i}: 909$.

14 Hopkins NFG. Abdominal aortic aneurysms. Br Med 7 1987;294:790-1.

15 Allen PIM, Gourevitch D, McKinley J, et al. Population screening for aortic aneurysms. Lancet 1987; ii: 736 .

16 Collin J, Araujo L, Walton J, Lindsell D. Oxford screening programme for abdominal aortic aneurysm in men aged 65 to 74 years. Lancet 1988;ii:613-5. 17 Scott RAP, Ashton H, Sutton GLJ. Ultrasound screening of a general practice population for aortic aneurysm. Br $\mathcal{F}$ S urg 1986;73:318

Accepted 13 October 1988

\section{Acquired immune deficiency syndrome \\ AIDS in the Nervous System. $R$ Lechtenberg, J Hollenberg Sher. (Pp 160; figs; £30.) New York: Churchill Livingstone, 1988. ISBN 0-443-08616-8.}

\section{Allergy}

Progress in Allergy. Vol 43. "Neuroimmunoendocrinology." Ed J E Blalock, K L Bost. Series editors K Ishizaka, P Kallós, P J Lachmann, B H Waksman. (Pp x+165; figs, colour plate; 192.75 .) Basel: Karger, 1988. Distributed by John Wiley and Sons.

\section{Anaesthesia}

Anaesthesiu and the Aged Patient. $\mathrm{Ed} \mathrm{H}$ T Davenport. (Pp 344; figs; $\{42.50$. Oxford: Blackwell Scientific, 1988. ISBN 0-632-01947-6.

Anaesthesia at the District Hospital. M B Dobson. (Pp 143; figs: \$16 paperback.) Geneva: World Health Organisation, 1988. ISBN 92-4-154228-4.

Anesthesia in Hepatic and Biliany Tract Disease. B R Brown Jr. (Pp 336; figs; $\$ 72.50$.) Philadelphia: Davis, 1988 ISBN 0-8036-1253-2.

Developments in Critical Care Medicine and Anesthesiology. "Common Perioperative Problems and the Anaesthetist." G M Woerlee. (Pp xiv +643 ; tist." G M Woerlee. (Pp xiv +643 , Dordrecht: Kluwer, 1988. ISBN 0-89838-402-8.

\section{Biochemistry}

Biochemistry: an Illustrated Outline. D J Williams. (Pp xvi+121; figs; \$4.95 paperback.) Philadelphia: LippincotU
London: Gower Medical, 1988. ISBN 0-397-44699-3.

The Receptors. "The alpha-2 Adrenergic Receptors." Ed L E Limbird. Series editor D B Bylund. (Pp 382; figs; $\$ 79.50$.) New Jersey: Humana Press, 1988. ISBN 0-89603-135-7.

\section{Biology}

Introduction to Practical Molecular Bio $\log$. P D Darbre. figs; (Pp 128; figs; 1988. ISBN 0-471-91965-9.

\section{Cardiology}

Developments in Cardiovascular Medicine 85. "Chronic Aortic Regurgit tion." Ed W H Gaasch, $\mathrm{H}$ J Levine. Pp xii+260; figs; 554.75 , Boston: Pp xil + 260; figs; 154.75. Boston: Press. ISBN 0-89838-364-1.

Developments in Cardiovascular Medicine. "Myocardial Energy Metabolism." Ed J W de Jong. (Pp xiv +298 figs; £52.) Dordrecht: Nijhoff, 1988 Distributed by MTP Press. ISBN 0-89838-394-3.

Developments in Cardiovascular Medicine. "Therapeutics in Cardiology." Ed A Bayés de Luna, A Betriu, Permanyer. (Pp xix +684; figs; $£ 89$.) Dordrecht: Kluwer, 1988. ISBN 0-89838-981-X.

Exercise Testing: Physiological, Biomechanical, and Clinical Principles. Naughton. (Pp 240; figs; \$35.) New York: Futura, 1988. ISBN 0-87993 245-7.

Non-invasive Cardiac Diagnosis. Ed L Mihóczy. (Pp 426; figs; $£ 27.50$. Budapest: Akadémiai Kiadó, 1988. ISBN 963-05-4823-2.

Noninvasive Cardiac Imaging: Recen
Developments. Ed R S Meltzer, Z Diabetes

Vered, H N Neufeld. (Pp 392; figs: \$75.) New York: Futura, 1988. ISBN 0-87993-314-3

\section{Cardiovascular disorders}

Vascular and Multi-Infarct Dementia. Ed J S Meyer, H Lechner, J Marshall, J F Toole. (Pp 288; figs; \$39.) New York: Futura, 1988. ISBN 0-87993323-2.

Cerebrovascular disorders

Pediatric Cerebrovascular Disorders. E S Roach, A R Riela. (Pp 272; figs; \$45.) New York: Futura, 1988. ISBN 0-87993-322-4.

\section{Child welfare}

Early Prediction and Prevention of Child Abuse. Ed K Browne, C Davies. P Stratton. $\mathrm{Pp} 336$; figs and colour plates; $£ 9.50$ paperback. Chichester W'ile, 1988 ISBN 0-471-91636-6.

\section{Community medicine}

A Place Like Home: a Radical Experment in Health Care. G Wilce. (Pp 144 £5.50 paperback.) London: Bedford Square Press, 1988. ISBN 0-7199. 1228-8

\section{Dermatology}

Essays on Leprosy by Oxford Medical Students Ed T J Ryan, A C McDougall. (Pp 192; figs; \&10 paperback, including postage and packing. Published for the St Francis Leprosy Guild by the Department of Dermatology, Slade Hospital, Headington, Oxford OX3 7JH. 1988
Clincal Diabetes: an Illustraled Text. Ed G M Besser, H J Bodansky, A G Cudworth. (Pp 304; colour plates: £52.) Philadelphia: Lippincot London: Gower Medical Publishing 1988. ISBN 0-397-44565-2.

\section{Respiratory medicine}

Diagnosic Tests in Respiratory Medicine. J Rees. (Pp 256; figs; £19.95 paperback.) London: Chapman and Hall, 1988. ISBN 0-412-28380-8.

Lung Biology in Health and Disease Vol 36. "Chronic Obstructive Pulmonary Disease: a Behavioural Perspective. "Ed A J McSweeny, I Grant Executwe Editor C Lenfant. Pp 344 1988. ISBN 0-82+7-7693-3.

Surfactants und the Lining of the L.ung. E M Scarpelli. (Pp 1+4; figs; £27. Baltimore: Johns Hopkins Universit Press, 1988. ISBN 0-8018-36633-6.

Social services

Community Social Work: a Paradigm for Change. G Smale, G Tuson, $M$ Cooper, M Wardle, D Crosbie. $\mathrm{Pp}$ 152; $£ 5$ including postage and packing.) 1988. Available from National Institute for Social Work: Practice an Development Exchange, 5-7 Tavistock Place, London WClH 9SS ISBN 0-902789-51-1.

Planning Investigative Projects: Workbook for Social Services Practitioners. C Addison. $\operatorname{Pp~60;£3.75}$ paperback 1988. Available from National Institute for Social Work: Practice and Development Exchange, 5-7 Tavistock Place, London WC1H 9SS. ISBN 0-902789-54-6.

\section{Statistics}

Statistical Techniques in Bioassay. Z Goivindarajulu. (Pp 180; £31.40.) Basel: Karger, 1988. Distributed by ohn Wiley and Sons. ISBN 3.8055 4630-0.

\section{Surgery}

Controversies in Breast Disease: Diagnosis and Management. Ed S Grundfest-Broniatowski, C B Esselstyn, Jr. (Pp 536; figs; \$180.) New York: Dekker, 1988. ISBN 0-8247-7880-4.

\section{Surgery - transplantation}

Organ Transplantation and Replacement. G J Cerilli. (Pp 752; figs; $£ 65$. Philadelphia: Lippincott, 1988. Distributed by Harper and Row. ISBN 0 397-50732-

\section{Third world}

Health Care in India. Yinong Shao. (Pp 48; £1.50 paperback.) Available from The Office of Health Economics, 12 Whitehall, London SWIA 2DY.

\section{Urology}

Overcoming Urinary Incontinence: a Simple Self-help Guide. R J Millard. Pp 128; £4.99 paperback.) Welling borough: Ther

\section{Virology}

Portraits of Viruses. A History of Virology. Ed F Fenner, A Gibbs. (Pp 352; 